\title{
Study on the Surface Integrity of a Thin-Walled Aluminum Alloy Structure after a Bilateral Slid Rolling Process
}

\author{
Laixiao Lu ${ }^{1}$, Jie Sun ${ }^{1, *}$, Xiong Han ${ }^{2}$ and Qingchun Xiong ${ }^{2}$ \\ 1 Key Laboratory of High Efficiency and Clean Mechanical Manufacture of Ministry of Education, \\ School of Mechanical Engineering, Shandong University, Jinan 250061, China; lulaixiao@163.com \\ 2 CAC Chengdu Aircraft Industrial (Group) Co., Ltd., Chengdu 610000, China; xiong-han@163.com (X.H.); \\ xiongqingchun@163.com (Q.X.) \\ * Correspondence: sunjie@sdu.edu.cn; Tel.: +86-531-88394593 (ext. 8)
}

Academic Editor: Nong Gao

Received: 3 March 2016; Accepted: 21 April 2016; Published: 26 April 2016

\begin{abstract}
For studying the influence of a bilateral slid rolling process (BSRP) on the surface integrity of a thin-walled aluminum alloy structure, and revealing the generation mechanism of residual stresses, a self-designed BSRP appliance was used to conduct rolling experiments. With the aid of a surface optical profiler, an X-ray stress analyzer, and a scanning electron microscope (SEM), the differences in surface integrity before and after BSRP were explored. The internal changing mechanism of physical as well as mechanical properties was probed. The results show that surface roughness ( $\mathrm{Ra}$ ) is reduced by $23.7 \%$, microhardness is increased by $21.6 \%$, and the depth of the hardening layer is about $100 \mu \mathrm{m}$. Serious plastic deformation was observed within the subsurface of the rolled region. The residual stress distributions along the depth of the rolling surface and milling surface were tested respectively. Residual stresses with deep and high amplitudes were generated via the BSRP. Based on the analysis of the microstructure, the generation mechanism of the residual stresses was probed. The residual stress of the rolling area consisted of two sections: microscopic stresses caused by local plastic deformation and macroscopic stresses caused by overall non-uniform deformation.
\end{abstract}

Keywords: bilateral slid rolling process (BSRP); surface integrity; aluminum alloys; thin-walled structure

\section{Introduction}

Aluminum alloys are widely used in the aviation industry due to its significant advantages, such as high specific strength, specific stiffness, anti-fatigue, etc. Aluminum alloys, titanium alloys, and composite materials are the three most important kinds of structural materials in modern aircraft. However, machining distortion is inevitable in machining processes for the aerospace monolithic components of aluminum alloys. The causes are numerous and diversified, including work blank residual stresses, machining stresses, stiffness variations in machining processes, and so on. To guarantee the high precision of parts, distortion correction processes are unavoidable for distorted aerospace monolithic components. A rolling method, which can introduce high-amplitude residual compressive stresses, can be used to correct the distorted components. The stresses will be redistributed after the rolling operations. Accordingly, the component configuration can be changed [1,2].

In rolling processes, a smooth wheel, roller, or ball with a high hardness is adopted to act on the part of the surfaces with a certain pressure for surface hardening, achieving residual compressive stresses. In 1929, this technology was firstly used in axles, crankshafts, and other parts for surface strengthening in Germany. Nowadays, after decades of development, it is widely used in aerospace, 
automotive motorcycle, precision machinery, bio-medicine, etc. [3,4]. Typical rolling technologies include burnishing, deep rolling (DR), and low plasticity burnishing (LPB). The main purpose of burnishing is to achieve a low surface roughness (Ra). However, it does not have much influence on residual stress [5]. The operation parameters and executing components of DR and burnishing are different. Since the rolling depth in DR is larger, a high compressive residual stress and a deep work hardening layer are obtained. Therefore, it is generally implemented at the outer surface of the key parts for strengthening, such as the shaft shoulder, crankshaft fillets, etc. [6,7]. In LPB processes, the most distinctive feature is that a carbide alloy or ceramic ball is motivated by the high-pressure liquid. As a result, a better Ra and deeper residual compressive stress can be obtained. Further, the defect of hardened material was also solved [8].

Recently, with the development of assistive technology, a variety of new burnishing methods have been proposed, such as the ultrasonic surface rolling process (USRP) [9], laser-assisted burnishing (LAB) [10], and cryogenic burnishing (CB) [11]. In the LAB processes, the workpiece surface layer is temporarily and locally softened by a controllable laser beam and then immediately processed by a conventional burnishing tool. LAB processes can produce a much better surface finish, a higher surface hardness, and a similar residual compressive stress compared with other conventional technologies used in hard materials, while the CB process is suited for a relatively soft metal like aluminum alloys. Research for rolling techniques mainly includes experimental, theoretical, and finite element simulation.

For the needs of practical application, substantial experimental research has been carried out to study the influence of parameters on surface integrity, including rolling depth, feed speed, rolling speed, the diameter of the wheel or ball, and the number of rolling passes [7]. Furthermore, multifarious prediction models have also been established based on experimental results. For example, Aysun et al. proposed a roughness prediction model and an optimization strategy of the ball burnishing process based on a desirability function approach and response surface methodology [12]. Yu et al. investigated the influences of parameters on surface integrity and established a prediction model for Ra and residual stress [13].

A surface strengthening mechanism was revealed through an analysis of microstructures. Avilés et al. and Juijerm et al. found that the fatigue lifetimes of rolled specimens at room and high temperatures were increased $[8,14]$. Zhu et al. found that the fatigue crack sources shifted from the surface to the second surface, which increased fatigue resistance ability [15]. Wang et al. found that the breakdown and corrosion potential of 40Cr were positively moved after the USRP, which indicated an improvement in corrosion resistance [9].

With the development of finite element technology, finite element modeling and a simulation method have been used in rolling analysis. Skalski et al. firstly proposed a two-dimensional finite element model of the rolling processes to analyze the changes of penetration depth under different pressures and roller diameters [5]. The problem is that a two-dimensional model cannot properly simulate the situation of the roller pressed into the workpiece. A three-dimensional model was firstly used to analyze the roll forming process of an annular groove by Kim et al. to study the influence of feed rate on residual stress [16]. However, the wheel or roller is often assumed as a rigid body in the finite element model in order to simplify the calculation, which affected the accuracy of the analysis. Rodríguez et al. considered the ball as a linear, elastic, and isotropic material, whereas the workpiece was an isotropic, plastic-hardening material with bilinear behavior, and the residual stress distribution accorded well with the experimental results [17].

Most of the research has focused on the outer cylindrical surface, the end surface, and the horizontal surface. Normally, an appropriative tool was installed on a lathe or machining center. However, there are structural restrictions when those rolling technologies are directly applied to monolithic components. The overall structures of these components are generally thin-walled parts with low structural rigidity. Unnecessary distortion will be introduced when the pressure is applied to one side. Therefore, bilateral slid rolling technology should be adopted in the correction processes of aerospace monolithic components. 
In the USRP, double rollers with symmetrical pressure act on both sides of the thin-wall structure to ensure that no additional torque is introduced. Wang et al. have tested the surface qualities (including $\mathrm{Ra}$, hardness, and the residual stresses of the surface) after the bilateral slid rolling process (BSRP) [1], but the variation mechanism of the thin-walled structure was not discussed. Since the particularity application of the BSRP, there has been little direct research. However, some surface treatment methods for aerospace monolithic components can still provide reference and guidance. Nam et al. presented a response surface methodology to optimize the surface properties of microhardness and residual stress in a shot peening process for aerospace structural components [18]. Nie et al. investigated the influence on high cycle fatigue resistance of laser shock peening (LSP) for the compressor blade made of TC11 titanium alloy. The relationship between fatigue characteristics and effects on residual stress and microstructural changes was established to reveal the strengthening mechanism of LSP [19]. Hennig et al. used the shot peening method with steel media in aerofoil, fillet, and annulus to introduce compressive residual stresses to increase the high cycle fatigue. The special designed caliper nozzles have been successfully utilized for different engine types in Rolls-Royce automobiles for five years [20].

Therefore, a self-designed BSRP appliance that is suitable for aerospace monolithic components was used to conduct the rolling experiments with a milled thin-walled aluminum alloy structure. The impact of rolling processes on surface integrity is discussed, addressing surface topography, microhardness, microstructure, and residual stress. The internal changing mechanism of physical as well as mechanical properties is revealed. Additionally, the generation mechanisms of residual stresses were probed by analyzing the microscopic plastic deformation and macroscopic non-uniform deformation.

\section{Materials and Methods}

\subsection{Experimental Materials}

The experiments were performed on a 60-mm-thick 7050-T7451 aluminum alloy sheet, which was manufactured by Kaiser Aluminum \& Chemical Corp, Oakland, CA, USA. The original residual stress was measured with the crack-compliance method. Figure 1 shows the locations of the samples and the stress distribution of the transverse profile along the thickness direction in the blank. Since the initial surface conditions have a critical influence on surface integrity, one of the end faces (XOY plane) of the sheet was milled first to imitate the condition of a processed surface. Then, two equally thin-walled structures, E1 and E2, were cut via wire electrical discharge machining to reduce the machining stresses. The E1 sample was used to conduct the tests of the surface profile and microstructure, and E2 sample was used to study the residual stress distribution. The sample size is $40 \times 20 \times 3 \mathrm{~mm}$, and the top half of the sample was rolled, which is marked with blue in Figure 1a.

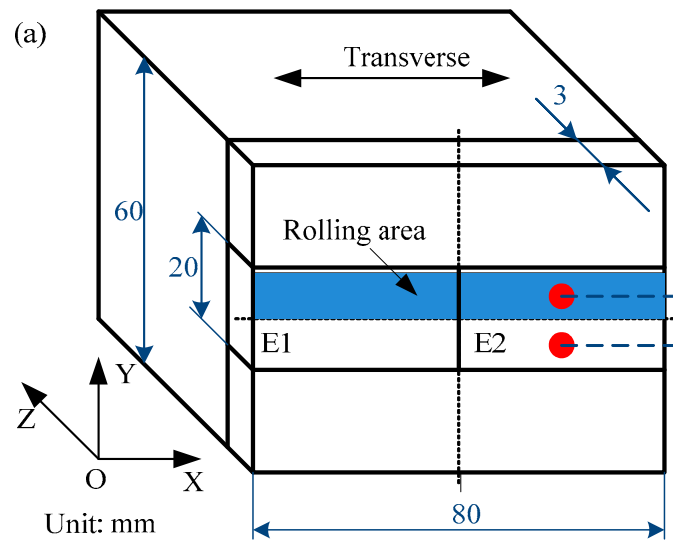

(b)

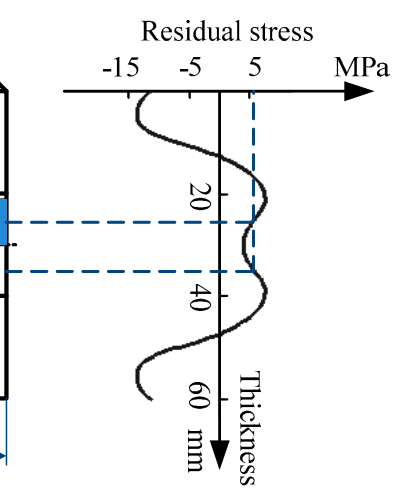

Figure 1. Experimental materials: (a) schematic of sampling location; (b) initial residual stress distribution of experimental blank. 


\subsection{The BSRP Appliance and Experimental Design}

Double rollers must be implemented on both sides of the rib with equal pressure due to the fact that the stiffness of aerospace monolithic components is low and easy to be distorted. To meet this requirement, the BSRP appliance was designed and manufactured, as shown in Figure 2a. The rollers with smooth surfaces were made of rolling bearings and mounted on two sliding blocks through bolts, respectively. One block was fixed to basal body, while another can be driven in a chute by a rotating preload nut. In the rolling process, the target component was first placed between the rollers. Then, the proposed preload force was applied by adjusting the preload nut. At the end, the rolling processes could be conducted by pulling the workpiece from one side to another. Figure $2 \mathrm{~b}$ shows the typical rolling processes of beam structures.

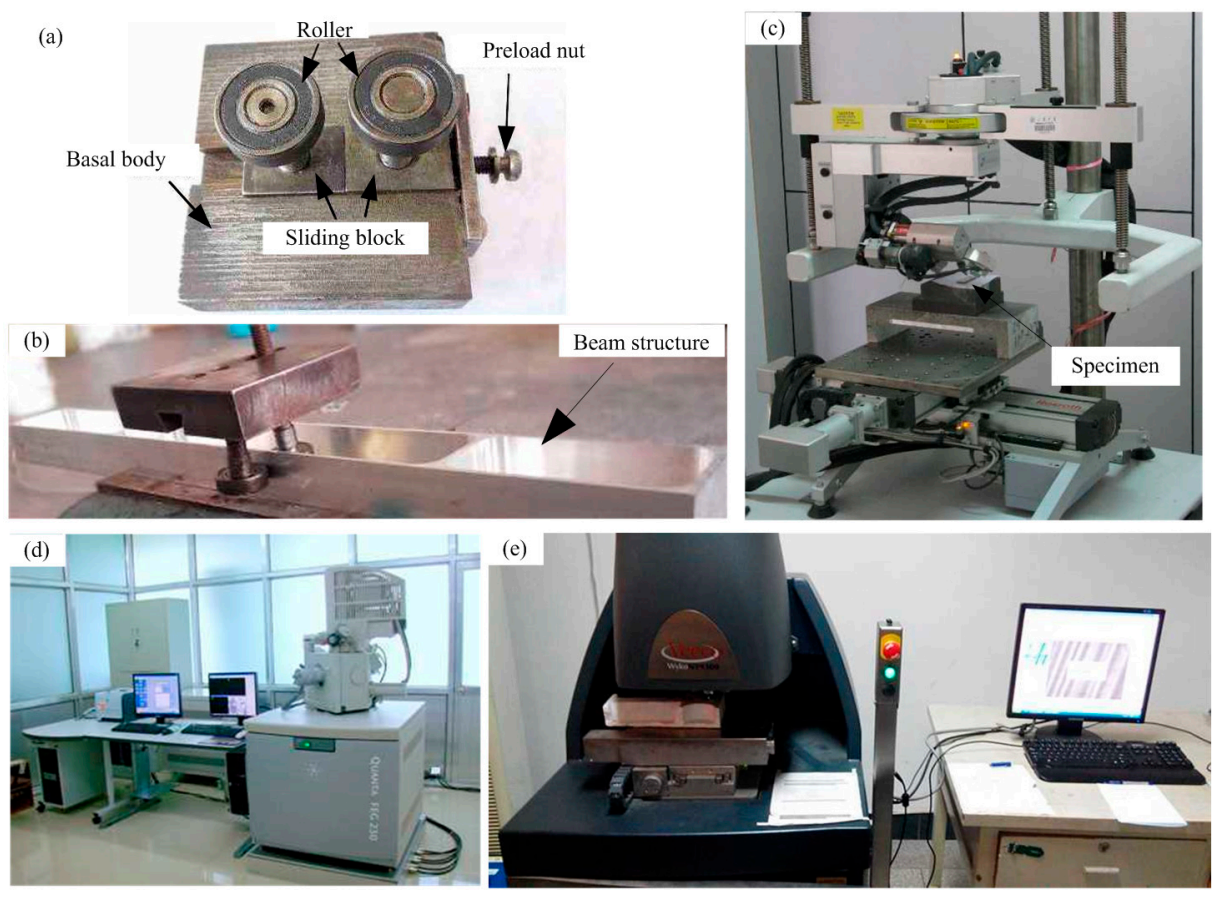

Figure 2. BSRP appliance and experimental processes: (a) BSRP appliance; (b) typical rolling processes of beam structures; (c) residual stresses test; (d) SEM system; (e) surface topography test.

In the rolling processes, the rolling depth is directly determined by the rotation angle of the preload nut. The materials of rollers bore steel GCr15 with an elastic modulus of $207 \mathrm{GPa}$, while the material of the target component was aluminum alloy 7050-T7451 with an elastic modulus of 71.7 GPa. In order to effectively control the rolling depth, a corresponding relation between the rotation angle of the preload nut and the rolling depth was established based on a large number of measurements. The relationship between the rotation angle and rolling depth is shown in Table 1.

Table 1. Quantitative relationship between the rotation angle and rolling depth.

\begin{tabular}{cc}
\hline Rotation Angles $\left({ }^{\circ}\right)$ & Rolling Depth $(\mathbf{m m})$ \\
\hline 45 & 0.03 \\
90 & 0.08 \\
135 & 0.11 \\
180 & 0.13 \\
225 & 0.15 \\
270 & 0.17 \\
\hline
\end{tabular}


In this experiment, the preload nut was rotated at $180^{\circ}$, so the rolling depth was $0.13 \mathrm{~mm}$. Each component was bi-directionally rolled to eliminate the effect of unevenness caused by single rolling. The diameter and thickness of the roller were $28 \mathrm{~mm}$ and $8 \mathrm{~mm}$, respectively. Since the rolling speed in correction operations was set in a very low level. There is no obvious change in surface integrity when the rolling speed is under such a low level. As a result, the rolling speed was set to $0.15 \mathrm{~m} / \mathrm{min}$.

\subsection{Measurement Equipment and Methods}

The milled side of the thin-walled structure, including the milling surface and the rolling surface, was selected to conduct the following tests. Surface topographies were observed by the NT9300 surface profiler (Veeco, Plainview, NY, USA). The MH-06 type microhardness tester (Everone Enterprisks Ltd., Shanghai, China) was used to measure the distribution of the microhardness. The experimental load was $10 \mathrm{~g}$, and the hold time was $5 \mathrm{~s}$. The microstructures of the cross sections were observed by the DMLM microscope system (Leica, Wetzlar, Germany) and the QF-250 scanning electron microscope (SEM) system (Bionand, Málaga, Spain). The X-Stress 3000 stress analyzer (Stresstech Oy, Vaajakoski, Finland) was used to measure the residual stress with a $\mathrm{Cr}$ target and diffraction angle of $139.3^{\circ}$. In order to test the residual stress distribution along the depth, the electrolytic polishing method was adopted to remove surface material step by step. The detailed tests processes are shown in Figure 2.

\section{Results}

\subsection{Surface Profile}

The surface profile of the junction region between rolled and milled regions is shown in Figure 3a. To compare the surface topography visually and take the impact of milling marks into consideration, two paths, as indicated by the black line in Figure 3a, were selected for the rolling surface and the milling surface, respectively. The profile data are plotted in Figure $3 \mathrm{~b}$. On the milling surface, the milling marks could be clearly differentiated, while the heights of the peaks were reduced in the rolling region. The material at the peaks was squeezed into valleys by the pressure of the rollers. As a result, shallow marks were filled. However, deeper marks could not be eliminated completely due to the restrictions of metal flow. The range of milling and rolling surfaces was reduced from $4.908 \mu \mathrm{m}$ to $3.142 \mu \mathrm{m}$, by $40.0 \%$. The roughness of the milling surface was $1.01 \mu \mathrm{m}$ and reduced to $0.77 \mu \mathrm{m}$ after the BSRP, by $23.7 \%$.

(a)

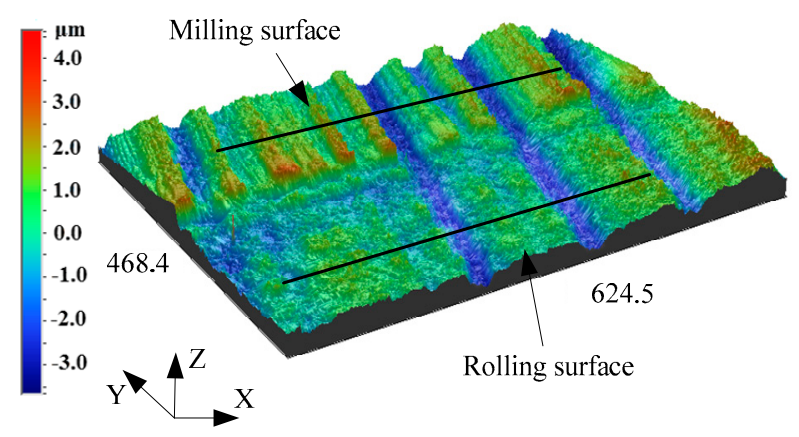

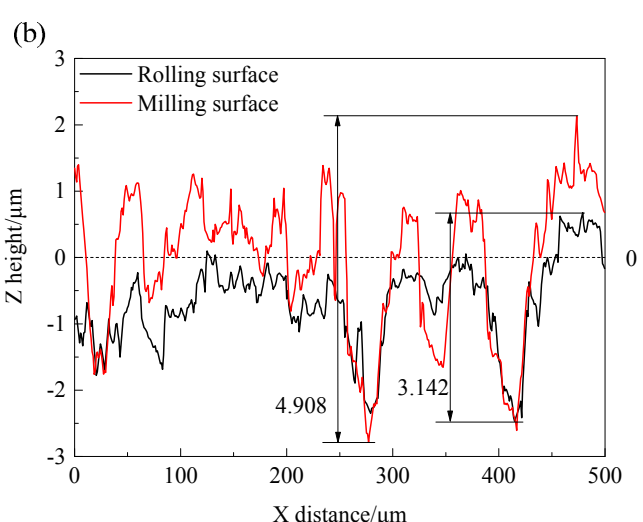

Figure 3. Surface topography: (a) surface topography comparison of rolling and milling surfaces; (b) morphological comparison of selected paths.

\subsection{Microhardness}

Microhardness distributions along the depths of the milling and rolling regions were tested three times, and the average value was calculated for further study. Figure 4 shows the microhardness 
distribution and the depth of the hardened layer. The microhardness of the milling surface was $104.6 \mathrm{HV}_{0.01}$. It improves with increases in depth and reaches a matrix value of $118 \mathrm{HV}_{0.01}$, indicated in Figure 4 by a dotted line, at a depth of $80 \mu \mathrm{m}$, while the surface microhardness of the rolling region is $127.2 \mathrm{HV}_{0.01}$ and decreases with increases in depth. It reaches the matrix hardness at approximately $100 \mu \mathrm{m}$ deep below the surface.

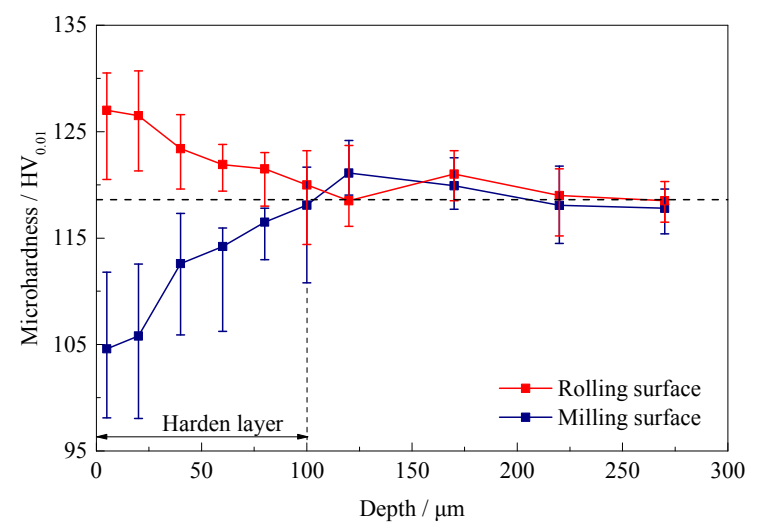

Figure 4. Distribution of microhardness along the depth.

For the milling surface, due to the influence of thermal and other factors during the machining processes, surface materials were softened. Therefore, the hardness of the milling surface is lower than that of the matrix material. However, in the rolling operation, severe plastic deformation and high amplitude stress were introduced to the rolling surface. As a result, the surface material was strengthened by rolling processes. The surface microhardness increased by $21.6 \%$, compared to the milling surface.

\subsection{Microstructure}

Figure 5 shows the positional relation of the microstructure for observing samples. The normal direction of the M2 section is perpendicular to the rolling direction, and the M1 sample is compared for the milling region. On the other hand, the normal directions of the M3 and M4 sections are parallel to the direction of the rolling region.

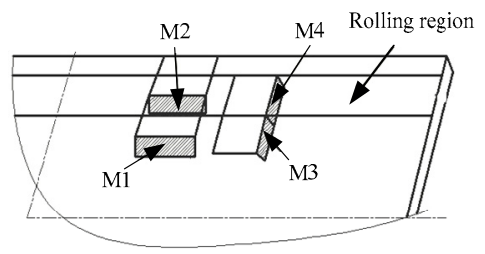

Figure 5. Schematic of samples' positional relation.

Figure 6 shows the variation of the microstructure after the rolling processes. In Figure $6 \mathrm{~b}$, the milling surface is not flat and has a lot of defects. However, surface defects are significantly reduced after rolling processes, as shown in Figure 6b. The rolling surface is smoother than the milling surface, which is indicated by the fact that it has a low friction coefficient and higher anti-corrosion ability. In rolling processes, the micro-peaks of the milling surface contacted with the harder rollers first. Then, the materials of micro-peaks were compacted, and flowed to valley areas due to severe plastic deformation caused by the differences in material hardness and rolling pressure. However, some deeper valleys could not be eliminated completely. 


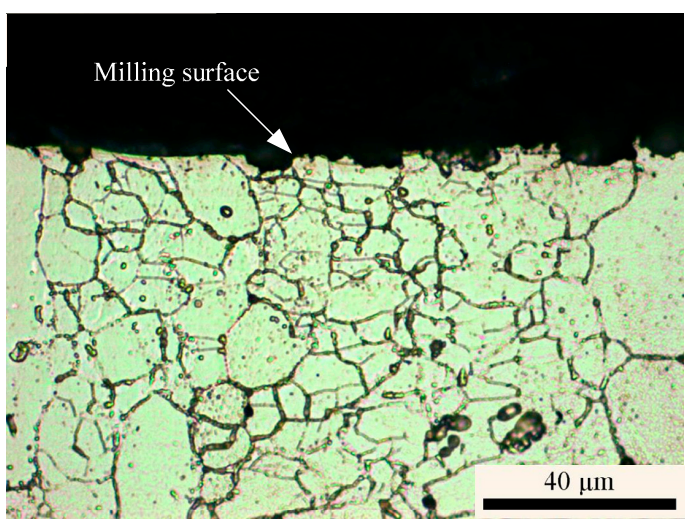

(a)

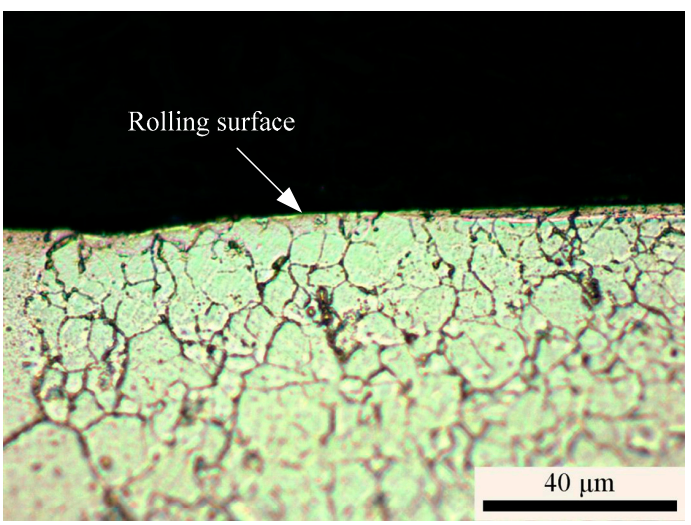

(b)

Figure 6. Microstructure comparison of specimens (×500): (a) M1 and (b) M2.

\subsection{Residual Stresses}

Residual stresses tests were conducted with the E2 sample. The direction of $X$ axis is defined in parallel to the rolling direction. Figure 7 shows the distributions of residual stresses along the depth.

From Figure 7, residual stresses distributions of the milling surface show a "spoon" shaped in both directions. The amplitude of residual compressive stresses exists on the milled surface, and it increases first and then decreases as depth increases. The residual stress at the surface is $-78.5 \mathrm{MPa}$ in the $X$ direction and reaches a maximum value of $-141.6 \mathrm{MPa}$ at a depth of $21 \mu \mathrm{m}$, while the value in the $Y$ direction is $-19.5 \mathrm{MPa}$ at the surface and reaches a maximum value of $-89.1 \mathrm{MPa}$ at a depth of $34 \mu \mathrm{m}$. The stresses of the $X$ direction recover to the levels of the matrix at a depth of $75 \mu \mathrm{m}$, while it is $110 \mu \mathrm{m}$ in the $Y$ direction.

The distribution characteristic and amplitude of residual stresses in the rolling region are significantly different from that of the milling region. For the rolling region, maximum compressive stress values were obtained at the surface with $-253.8 \mathrm{MPa}$ and $-217.1 \mathrm{MPa}$ in the $X$ and $Y$ directions, respectively. The value of the residual compressive stress decreases as depth increases. According to the slope of the curve, the residual stress layer can be divided into three areas: the significant impact region, the smooth transition region, and the region in which the effect disappeared. The significant impact region was located from the surface to $150 \mu \mathrm{m}$ deep. In this region, residual stress was significantly affected by rolling processes and increased as depth increased, while the residual stress was relatively stable at approximately -100 MPa from $150 \mu \mathrm{m}$ deep to $500 \mu \mathrm{m}$ deep below the surface. This layer was defined as the smooth transition region. Next is the disappeared effect region. In this region, the residual stress decreased rapidly and reached the matrix stress status at depths of $600-700 \mu \mathrm{m}$.

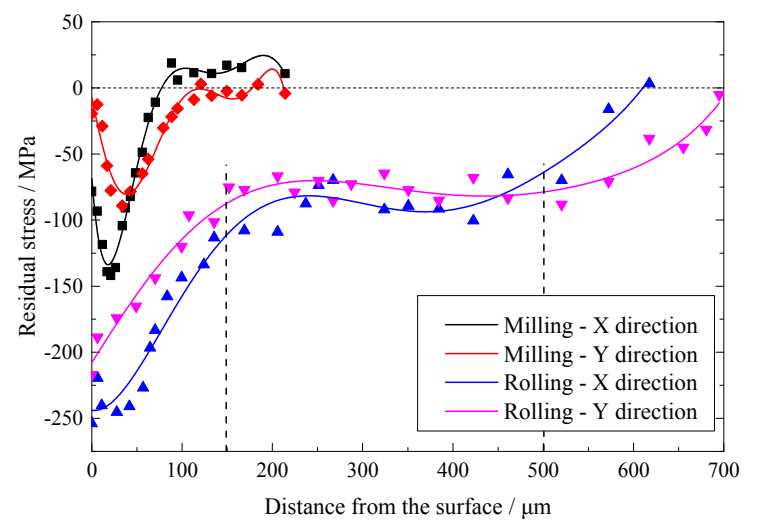

Figure 7. Distribution of residual stresses along the depth. 


\section{Discussion}

\subsection{Variation Mechanisms of the Rolling Surface}

The surface strengthening mechanism was further discussed based on the variation in the microstructure. Figure 8 shows the typical microstructures of the rolling and milling region. On the milling surface, the defects can be clearly observed, whereas the rolling surface is smooth, and the boundary line of the rolling surface is more regular than that of the milling surface. Due to the plastic deformation of the surface materials, the milling trace, which is one of the major factors that affect surface quality, was reduced by the rolling processes. This corresponds to the vibration of the surface profile. It is suggested that the rolling processes could be used in improving the surface quality for aerospace monolithic components.

In conventional rolling processes, with a high rolling speed and pressure, surface grains are pronounced deformed, and metal flow traces can be clearly observed on the shallow surface. The surface region for rolling-treated specimens can then be divided into two zones from the surface to the core: the refined-grain zone and the coarse-grain zone [21]; however, in this study, the rolling surface had only a very tiny metal flow traces after the BSRP, as shown in Figure $8 b$,d. The region with metal flow traces was defined as the refined-microstructure zone. The depth of the refined-microstructure zone is approximately determined on the basis of visual analysis of the microstructure [22]. The average depth of the refined-microstructure zone induced by the BSRP is about $5 \mu \mathrm{m}$, as shown in Figure 8b. However, the refined-microstructure zone could not be clearly distinguished in Figure 8d. Comparing samples M2 and M4, the cross section of sample M2 is perpendicular to the rolling direction. It is suggested that the flow of material caused by rolling processes is mainly along the rolling direction, while plastic strain is hardly noted after the milling process in Figure 8a,c.

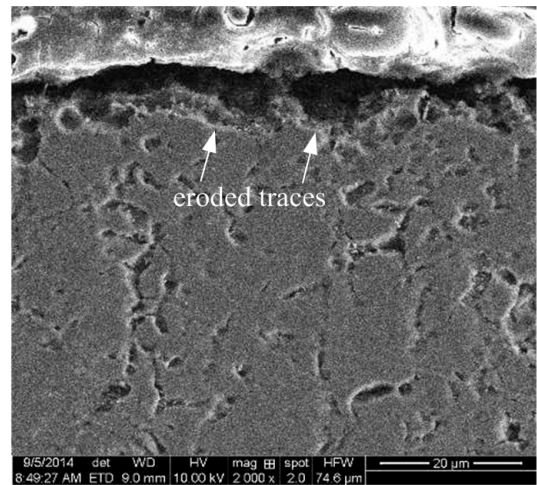

(a)

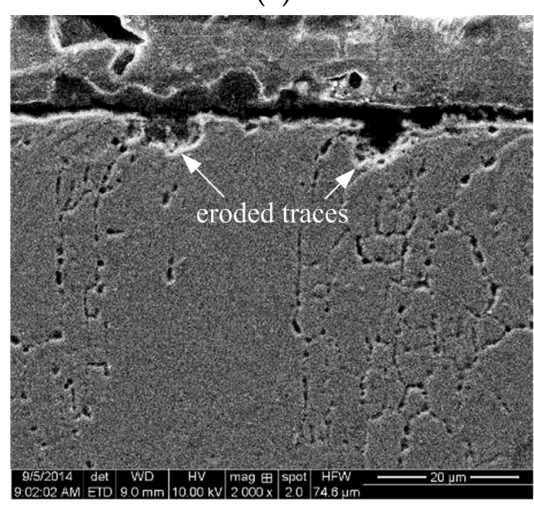

(c)

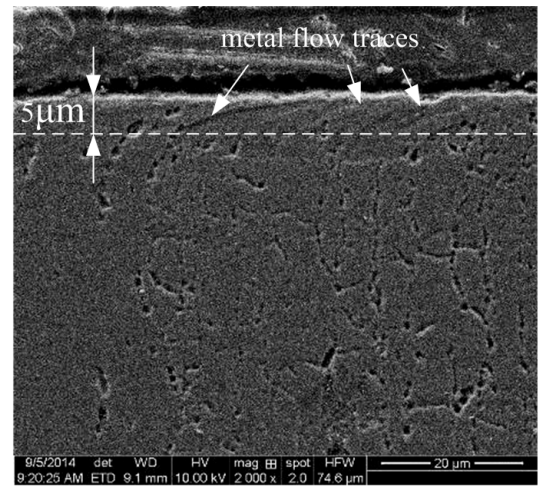

(b)

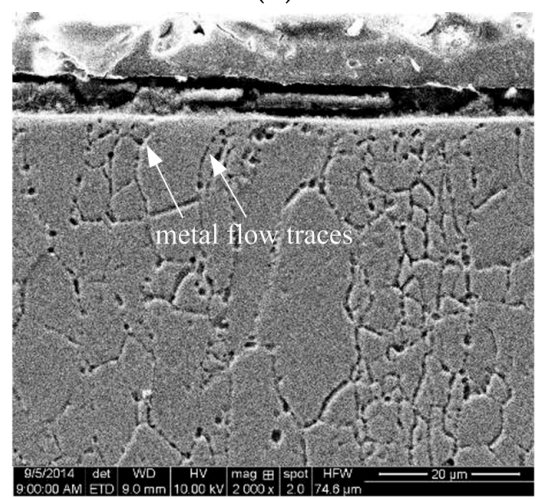

(d)

Figure 8. SEM photographs of specimens (×2000): (a) M1; (b) M2; (c) M3; and (d) M4. 
In the refined-microstructure zone, slipping is hard for the grains with "hard" orientations, leading to the formation of dislocations in the interior of the grains [23]. The dislocation proliferation happened on the surface after the rolling led to the increase of dislocation density. Thus, work hardening resulted from the increased plastic deformation and dislocation. Figure 4 shows that, as a consequence, the profile of the microhardness distribution beneath the surface is altered.

These refined surface layers with higher hardness and compressive residual stress due to the mechanism of severe plastic deformation and dislocation would provide benefits to enhance the mechanical and physical properties of the components, such as improving their corrosion/wear resistance and increasing their fatigue lives [11]. During the preparation operations of the samples, surfaces were corroded to different extents, although the corrosion time was equal. It can be observed in Figure 8a,c that the remarkable eroded traces could be found. However, the rolling surface shows no discernible evidence of corrosion. The superficial area was decreased after the rolling processes, so the corrosion quantity was also reduced. It is indicated that the surface corrosion resistance ability was improved by the rolling processes.

\subsection{Generation Mechanism of Residual Stresses}

Residual stresses in the rolling region were closely related with the rolling effect. The distribution of full-width-at-half-maximum (FWHM) along the depth was also obtained by the X-ray diffraction method, as shown in Figure 9. The FWHM describes the width of the diffraction peaks. It is related to the heat treatment, surface hardening, and other microscopic residual stresses caused by the grain size and the value of deformation and dislocation density [14,24]. In Figure 9b, the FWHM of the rolling surface is higher than the milling surface. The depth of the affected layer is up to $50 \mu \mathrm{m}$, which is indicated by the fact that severe plastic deformation and dislocation were generated by rolling processes in the surface and subsurface grains. With the emergence of dislocations, the microscopic residual stresses were introduced to the surface material.

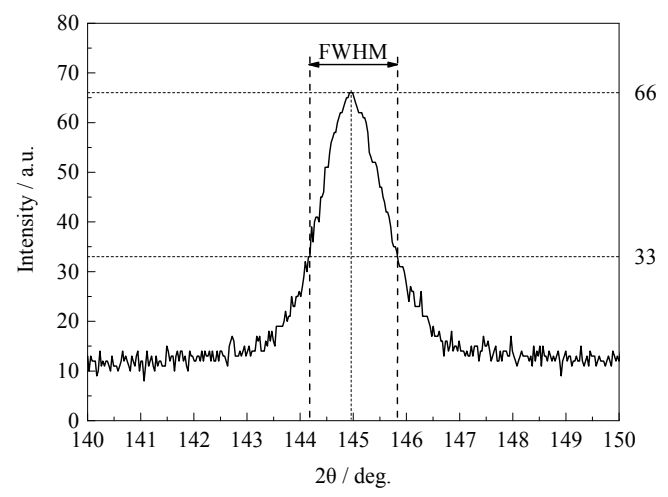

(a)

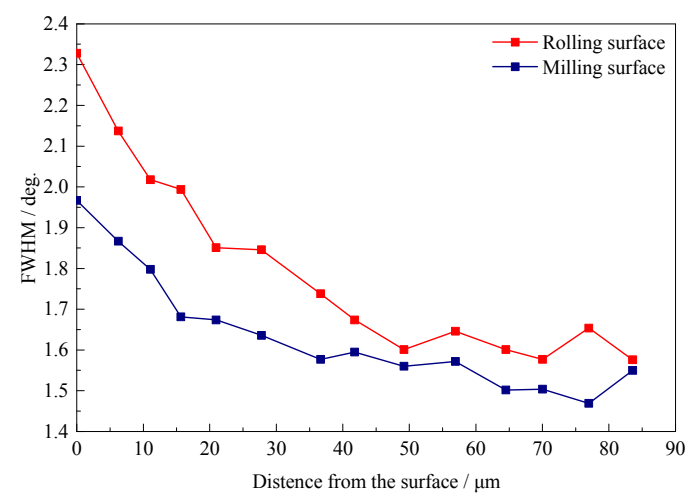

(b)

Figure 9. Distribution of full-width-at-half-maximum (FWHM) along the depth: (a) intensity profile; (b) FWHM distribution.

This phenomenon can be explained by analyzing the microstructures. After rolling processes, the materials in the surface region were flattened and elongated under the pressure of rollers, as shown in Figure 10. The original shape and positional relationship of the grains were changed by this uneven deformation. As a result, interacting forces between distorted grains were generated, as shown in Figure 10b. This force was presented as residual compressive stresses, which exist in the entire rolling region. These phenomena were consisted of severe plastic deformations and metal flow traces in the surface and subsurface, as shown in Figure $7 \mathrm{~b}, \mathrm{~d}$. 


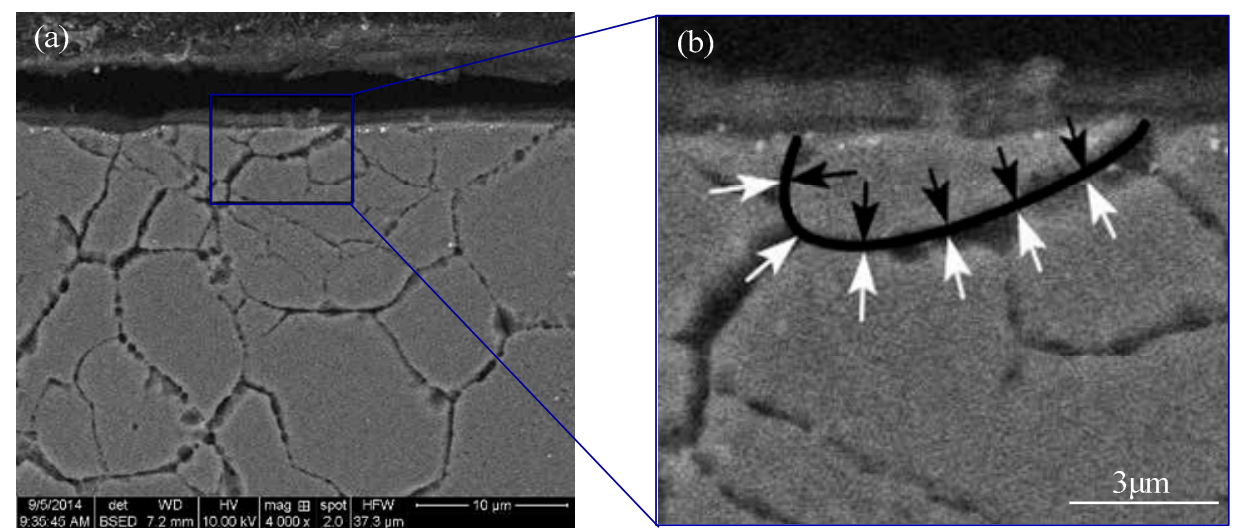

Figure 10. Distribution of intergranular forces: (a) Specimen M2 $(\times 4000)$ and (b) schematic of intergranular forces.

Since only half of the structure was rolled, there were two kinds of macroscopic deformation in the thin-walled structure after the BSRP. For the rolled region, the surface materials were plastically deformed, and the center materials were elastically deformed. For the whole structure, it was bent under the effect of residual stresses and micro-plastic deformation.

Under the pressure of rollers, the materials at the peaks flowed into nearby valleys. In the rolling processes, the materials of the surface layer were plastically deformed, while materials in the deep layer were only passively elastically deformed and would recover after rolling, as shown in Figure 11. As a result, macroscopic residual compressive stresses were developed in the surface materials, while residual tensile stresses were obtained in the elastically deformed region.

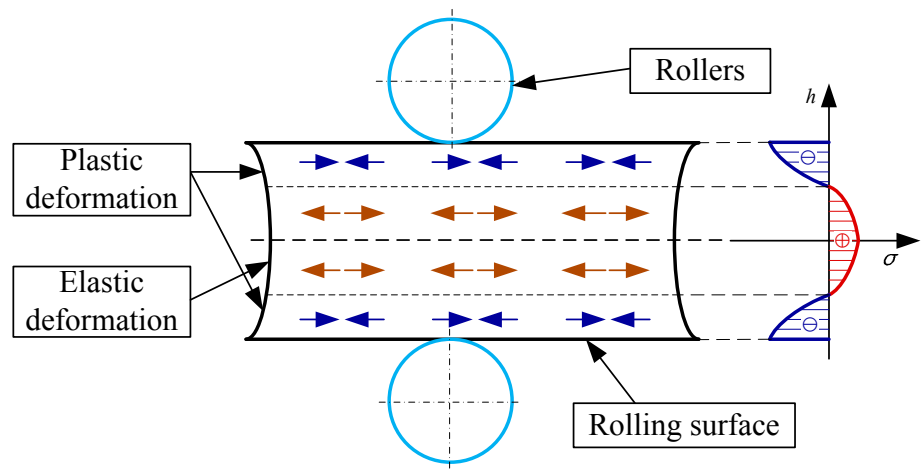

Figure 11. Schematic of deformation and residual stresses caused by rolling processes.

In the rolling process, only the upper half part was rolled. According to the results of the residual stresses, deep and high amplitude compressive stresses were generated in the rolling region via this kind of local rolling process. If the effect of the structure depth was ignored, the residual stresses were equivalent to an average value, as shown in Figure 12a. The thin-walled structure was easily distorted due to its low stiffness, since the introduced residual stresses and micro-plastic deformation in the whole structure were unbalanced. The structure was bent under the effect of residual stress and micro-plastic deformation. As a result, macroscopic stress was generated, as shown in Figure 12b. Essentially, the residual stresses introduced by the rolling processes was the result of the re-equilibrium of stresses caused by micro-plastic deformation and macro-bending deformation in the thin-walled structure, as shown in Figure 12c. 


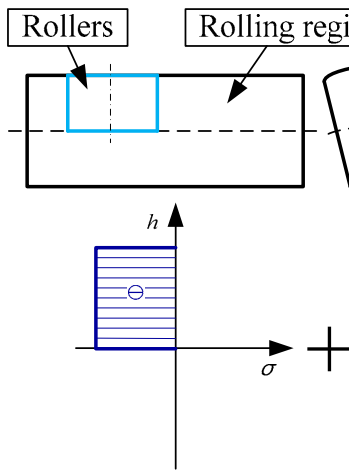

(a)
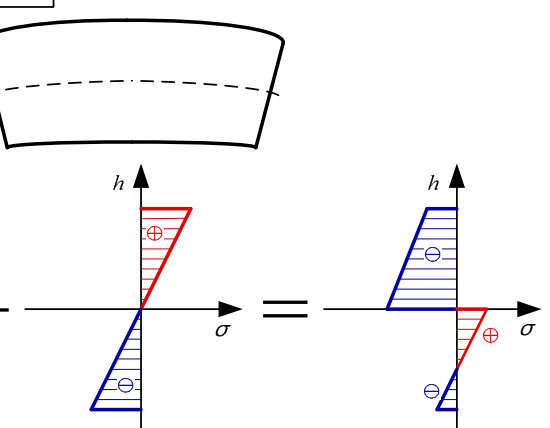

(b)

(c)

Figure 12. Residual stresses caused by local rolling processes: (a) rolling stress; (b) bending stress; (c) combined stress.

\section{Conclusions}

Self-designed bilateral slid rolling equipment was employed in aluminum alloy thin-walled structure rolling processes. The surface integrity as well as the strengthening mechanism of the rolled surface was analyzed after the BSRP.

(1) The surface integrity of the aluminum alloy 7050-T7451 was significantly improved by the BSRP. After the rolling processes, surface defects prominently reduced. Specifically, Ra reduced by $23.7 \%$ from 1.01 to $0.77 \mu \mathrm{m}$, surface microhardness increased by $21.6 \%$, and the hardened layer depth was up to $100 \mu \mathrm{m}$.

(2) Flowing traces of surface materials were observed in the rolling region within the sample cross section. It was indicated that the surface grains were plastically deformed under the pressure of the rollers, which is also considered to be the main reason for surface hardening and the generation of residual stresses.

(3) Deep and high amplitude residual compressive stresses were obtained in the rolling processes. According to the influence degree, the residual stress layer can be divided into three regions: the significant impact region, the smooth transition region, and the region in which the effect disappeared. Based on the distribution of the FWHM and the surface microstructures, generation mechanisms of residual stresses are revealed.

Acknowledgments: The authors want to thank the National Natural Science Foundation of China (No. 51275277) for the support.

Author Contributions: L. Lu contributed to the experimental testing and wrote the manuscript under the guidance of J. Sun. X. Han contributed to the design and manufacture of the BSRP appliance. Q. Xiong conducted the residual stresses tests and revised the manuscript.

Conflicts of Interest: The authors declare no conflicts of interest.

\section{References}

1. Wang, Z.Q. Study on Theory and Approach for Correcting Aerospace Monolithic Component Due to Machining Distortion Using Rolling Method. Ph.D. Thesis, Shandong University, Jinan, China, 2009.

2. Wang, Z.Q.; Li, J.F.; Sun, J.; Li, G.Y. FEM analysis of deformation correction by side-wall rolling of aircraft monolithic components. China Mech. Eng. 2009, 10, 612-616.

3. Uddin, M.S.; Hall, C.; Murphy, P. Surface treatments for controlling corrosion rate of biodegradable Mg and Mg-based alloy implants. Sci. Technol. Adv. Mat. 2015. [CrossRef]

4. Zhao, J.; Xia, W.; Li, F.L.; Zhou, Z.Y. Research status and developing tendency of burnishing mechanism. Tool Eng. 2010, 44, 3-8.

5. Skalski, K.; Morawski, A.; Przybylski, W. Analysis of contact elastic-plastic strains during the process of burnishing. Int. J. Mech. Sci. 1995, 37, 461-472. [CrossRef] 
6. Altenberger, I. Deep Rolling-the past, the present and the future. In Proceedings of the 9th International Conference for Shot Peening, Paris, France, 6-9 September 2005.

7. Beghini, M.; Bertini, L.; Monelli, B.D.; Santus, C.; Bandini, M. Experimental parameter sensitivity analysis of residual stresses induced by deep rolling on 7075-T6 aluminium alloy. Surf. Coat. Technol. 2014, 254, 175-186. [CrossRef]

8. Avilés, R.; Albizuri, J.; Rodríguez, A.; de Lacalle, L.N.L. Influence of low-plasticity ball burnishing on the high-cycle fatigue strength of medium carbon AISI 1045 steel. Int. J. Fatigue 2013, 55, 230-244. [CrossRef]

9. Wang, T.; Wang, D.; Liu, G.; Gong, B.; Song, N. Investigations on the nanocrystallization of 40Cr using ultrasonic surface rolling processing. Appl. Surf. Sci. 2008, 255, 1824-1829. [CrossRef]

10. Tian, Y.; Shin, Y.C. Laser-assisted burnishing of metals. Int. J. Mach. Tool Manu. 2007, 47, 14-22. [CrossRef]

11. Huang, B.; Kaynak, Y.; Sun, Y.; Jawahir, I.S. Surface layer modification by cryogenic burnishing of Al 7050-T7451 alloy and validation with FEM-based burnishing model. Procedia CIRP 2015, 31, 1-6. [CrossRef]

12. Sagbas, A. Analysis and optimization of surface roughness in the ball burnishing process using response surface methodology and desirabilty function. Adv. Eng. Softw. 2011, 42, 992-998. [CrossRef]

13. Yu, X.; Sun, J.; Li, S.T.; Li, J.F. Influences of burnishing process on surface quality integrity of EA4T axles and establishment of prediction model. China Surf. Eng. 2014, 27, 87-95. [CrossRef]

14. Juijerm, P.; Altenberger, I. Fatigue behavior of deep rolled Al-Mg-Si-Cu alloy at elevated temperature. Scr. Mater. 2006, 55, 943-946. [CrossRef]

15. Zhu, Y.L.; Li, L.; Wang, K.; Huang, Y.L. An integrated ultrasonic deep rolling and burnishing technology for anti-fatigue manufacturing. J. Mech. Eng. 2009, 45, 183-186. [CrossRef]

16. Kim, W.; Kawai, K.; Koyama, H.; Miyazaki, D. Fatigue strength and residual stress of groove-rolled products. J. Mater. Process. Technol. 2007, 194, 46-51. [CrossRef]

17. Rodríguez, A.; de Lacalle, L.N.L.; Celaya, A.; Lamikiz, A.; Albizuri, J. Surface improvement of shafts by the deep ball-burnishing technique. Surf. Coat. Technol. 2012, 206, 2817-2824. [CrossRef]

18. Nam, Y.; Jeong, Y.; Shin, B.; Byun, J. Enhancing surface layer properties of an aircraft aluminum alloy by shot peening using response surface methodology. Mater. Des. 2015, 83, 566-576. [CrossRef]

19. Nie, X.; He, W.; Zang, S.; Wang, X.; Zhao, J. Effect study and application to improve high cycle fatigue resistance of TC11 titanium alloy by laser shock peening with multiple impacts. Surf. Coat. Technol. 2014, 253, 68-75. [CrossRef]

20. Hennig, W.; Feldmann, G.; Haubold, T. Shot peening method for aerofoil treatment of blisk assemblies. Proced. CIRP 2014, 13, 355-358. [CrossRef]

21. Cheng, M.; Zhang, D.; Chen, H.; Qin, W. Development of ultrasonic thread root rolling technology for prolonging the fatigue performance of high strength thread. J. Mater. Process. Technol. 2014, 214, 2395-2401. [CrossRef]

22. Wu, B.; Wang, P.; Pyoun, Y.; Zhang, J.; Murakami, R. Study on the fatigue properties of plasma nitriding S45C with a pre-ultrasonic nanocrystal surface modification process. Surf. Coat. Technol. 2013, 216, 191-198. [CrossRef]

23. Zhao, J.; Xia, W.; Li, N.; Li, F.L. A gradient nano/micro-structured surface layer on copper induced by severe plasticity roller burnishing. Trans. Nonferr. Met. Soc. China 2014, 24, 441-448. [CrossRef]

24. Li, Y.; Li, J.Y.; Liu, M.; Ren, Y.Y.; Chen, F.; Yao, G.C.; Mei, Q.S. Evolution of microstructure and property of NiTi alloy induced by cold rolling. J. Alloy. Compd. 2015, 653, 156-161. [CrossRef]

(C) 2016 by the authors; licensee MDPI, Basel, Switzerland. This article is an open access article distributed under the terms and conditions of the Creative Commons Attribution (CC-BY) license (http://creativecommons.org/licenses/by/4.0/). 